\title{
Should use of 4 hours continuous positive airway pressure per night be considered acceptable compliance?
}

\author{
Juan F. Masa ${ }^{1,2}$ and Jaime Corral-Peñafiel ${ }^{1,2}$
}

Affiliations: ${ }^{1}$ Dept of Pneumology, San Pedro de Alcantara Hospital, Caceres, Spain. ${ }^{2}$ CIBER de enfermedades respiratorias (CIBERES), Madrid, Spain.

Correspondence: Juan F. Masa, Dept of Pneumology, San Pedro de Alcantara Hospital, Avd Pablo Naranjo s/n, Caceres 10003, Spain. E-mail: fmasalasepar.es

@ERSpublications

CPAP use can determine the cardiovascular risk reduction; physicians must endeavour to get the best CPAP use http://ow.ly/zPZbP

Continuous positive airway pressure (CPAP) reduces blood pressure in obstructive sleep apnoea (OSA) patients, as well as in patients with resistant hypertension. The effect of CPAP is directly related to treatment compliance [1-3]. Observational studies have shown a reduction in cardiovascular mortality risk in severe OSA patients treated with CPAP and adequate compliance [4-6]. A recent randomised controlled trial (RCT) showed a reduction in cardiovascular events (including hypertension incidence) in patients with adequate CPAP compliance [7]. However, what is an adequate definition of CPAP compliance?

Ideally, CPAP compliance should take place for as long as the patient is sleeping but, in practice, this occurs in a minority of subjects. Based on several studies, compliance of $\geqslant 4 \mathrm{~h}$ per night has been considered acceptable. However, dose-response studies have found that different compliance levels achieve different dimensions of clinical improvement [8-11]. For instance, in order to obtain an improvement in Epworth sleepiness scale at least $4 \mathrm{~h} \cdot$ night $^{-1}$ of CPAP is required [8], $6 \mathrm{~h} \cdot$ night $^{-1}$ is required for multiple sleep latency test and memory $[8,11]$ and $7.5 \mathrm{~h} \cdot$ night $^{-1}$ for functional outcome associated with a sleepiness questionnaire [8]. Therefore, is there a CPAP compliance level to obtain a reduction in cardiovascular risk?

There is little information about the necessary CPAP compliance needed to decrease cardiovascular risk. In an observational study, cardiovascular mortality was reduced in OSA patients with CPAP compliance of $\geqslant 4 \mathrm{~h} \cdot$ night $^{-1}$ [4]. In another observational study, mortality (mainly from cardiovascular causes) decreased with night-time CPAP use of 1-6 h.night ${ }^{-1}$ but decreased more acutely with a compliance of $\geqslant 6 \mathrm{~h} \cdot$ night $^{-1}[5]$. In a recent RCT, reduction of blood pressure in OSA patients with hypertension required $5.6 \mathrm{~h} \cdot \mathrm{night}^{-1}$ of CPAP [2] and compliance of $5.96 \mathrm{~h} \cdot$ night $^{-1}$ decreased the incidence cardiovascular events (including hypertension) [7].

Several studies have explored potential CPAP compliance improvement by adding simple or combined strategies to the standard management [12-17]. Accordingly, CPAP use increased in $>1 \mathrm{~h} \cdot$ night $^{-1}$ producing clinical improvement. In this issue of the European Respiratory Journal, BOULOUKAKI et al. [18] present results from the largest RCT on this topic comparing the effect of multidimensional versus standard strategies on CPAP compliance for 2 years of follow-up. The authors randomised 3100 newly diagnosed OSA patients to the standard group or the intensive group. Night-time CPAP use improved on average by $>1.7 \mathrm{~h}$ with the multidimensional intervention than with the standard one. This resulted in an important clinical improvement but the most significant data showed that cardiovascular event incidence decreased by $50 \%$. Hospitalisations due to new cardiovascular events occurred in 45 (2.9\%) patients in the multidimensional strategy and in $96(6.2 \%)$ in the standard strategy. From these, fatal events occurred

Received: July 022014 | Accepted: July 182014

Conflict of interest: None declared.

Copyright @ERS 2014 
in $1.8 \%$ and in $4 \%$ of patients, respectively. To put these data into perspective, we present the results of the study by MARIN et al. [4]. Cardiovascular incidence for 2 years was $1.28 \%$ and cardiovascular mortality was $0.7 \%$ for patients with severe OSA with $\geqslant 4 \mathrm{~h}$ of CPAP use. Although these data seem lower than in the study by BOULOUKAKI et al. [18], in another large RCT the subgroup with better CPAP compliance $\left(5.96 \mathrm{~h} \cdot\right.$ night $\left.^{-1}\right)$ had an estimated cardiovascular incidence (without hypertension incidence) of $7.3 \%$ for 2 years [7].

In the study by BOULOUKAKI et al. [18], the multidimensional intervention was an independent factor used to explain cardiovascular mortality reduction. This means that an increase of $1.7 \mathrm{~h} \cdot$ night $^{-1}$ resulted in a survival improvement. In addition, another independent factor of mortality was CPAP use for

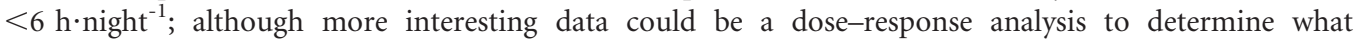
CPAP compliance level would result in a survival improvement.

Another important aspect of the study by BOULOUKAKI et al. [18] was the economical evaluation, which took into account the intervention burden and the economical saving caused by the prevention of hospital admissions due to cardiovascular problems. This resulted in an incremental burden of $€ 100$ with a saving of $€ 41713$. Unfortunately, the study was not designed to analyse cost-effectiveness. It is very important to transfer the results from clinical research assessing efficacy directly into healthcare systems and the public.

In summary, the present study shows that achieving better CPAP compliance using an active intervention decreases cardiovascular mortality and suggests CPAP use of $\geqslant 6 \mathrm{~h} \cdot$ night $^{-1}$. Future studies using doseresponse evaluation and cost-effectiveness analysis would be welcomed

\section{References}

1 Martínez-García MA, Capote F, Campos-Rodríguez F, et al. Effect of CPAP on blood pressure in patients with obstructive sleep apnea and resistant hypertension: the HIPARCO randomized clinical trial. JAMA 2013; 310: 2407-2415.

2 Barbé F, Durán-Cantolla J, Capote F, et al. Long-term effect of continuous positive airway pressure in hypertensive patients with sleep apnea. Am J Respir Crit Care Med 2010; 181: 718-726.

3 Haentjens P, Van Meerhaeghe A, Moscariello A, et al. The impact of continuous positive airway pressure on blood pressure in patients with obstructive sleep apnea syndrome: evidence from a meta-analysis of placebo-controlled randomized trials. Arch Intern Med 2007; 167: 757-764.

4 Marin JM, Carrizo SJ, Vicente E, et al. Long-term cardiovascular outcomes in men with obstructive sleep apnoeahypopnoea with or without treatment with continuous positive airway pressure: an observational study. Lancet 2005; 365: 1046-1053.

5 Campos-Rodriguez F, Martinez-Garcia MA, de la Cruz-Moron I, et al. Cardiovascular mortality in women with obstructive sleep apnea with or without continuous positive airway pressure treatment: a cohort study. Ann Intern Med 2012; 156: 115-122.

6 Martínez-García MA, Campos-Rodríguez F, Catalán-Serra P, et al. Cardiovascular mortality in obstructive sleep apnea in the elderly: role of long-term continuous positive airway pressure treatment: a prospective observational study. Am J Respir Crit Care Med 2012; 186: 909-916.

7 Barbé F, Durán-Cantolla J, Sánchez-de-la-Torre M, et al. Effect of continuous positive airway pressure on the incidence of hypertension and cardiovascular events in nonsleepy patients with obstructive sleep apnea: a randomized controlled trial. JAMA 2012; 307: 2161-2168.

8 Weaver TE, Maislin G, Dinges DF, et al. Relationship between hours of CPAP use and achieving normal levels of sleepiness and daily functioning. Sleep 2007; 30: 711-719.

9 Antic NA, Catcheside P, Buchan C, et al. The effect of CPAP in normalizing daytime sleepiness, quality of life, and neurocognitive function in patients with moderate to severe OSA. Sleep 2011; 34: 111-119.

10 Stradling JR, Davies RJ. Is more NCPAP better? Sleep 2000; 23: Suppl. 4, S150-S153.

11 Zimmerman ME, Arnedt JT, Stanchina M, et al. Normalization of memory performance and positive airway pressure adherence in memory-impaired patients with obstructive sleep apnea. Chest 2006; 130: 1772-1778.

12 Lettieri CJ, Walter RJ. Impact of group education on continuous positive airway pressure adherence. J Clin Sleep Med 2013; 9: 537-541.

13 Meurice JC, Ingrand P, Portier F, et al. A multicentre trial of education strategies at CPAP induction in the treatment of severe sleep apnoea-hypopnoea syndrome. Sleep Med 2007; 8: 37-42.

14 Falcone VA, Damiani MF, Quaranta VN, et al. Polysomnograph chart view by patients: a new educational strategy to improve CPAP adherence in sleep apnea therapy. Respir Care 2014; 59: 193-198.

15 Damjanovic D, Fluck A, Bremer H, et al. Compliance in sleep apnoea therapy: influence of home care support and pressure mode. Eur Respir J 2009; 33: 804-811.

16 Lai AY, Fong DY, Lam JC, et al. The efficacy of a brief motivational enhancement education program on CPAP adherence in OSA: a randomized controlled trial. Chest 2014; 146: 600-610.

17 Olsen S, Smith SS, Oei TP, et al. Motivational interviewing (MINT) improves continuous positive airway pressure (CPAP) acceptance and adherence: a randomized controlled trial. J Consult Clin Psychol 2012; 80: 151-163.

18 Bouloukaki I, Giannadaki K, Mermigkis C, et al. Intensive versus standard follow-up to improve continuous positive airway pressure compliance. Eur Respir J 2014; 44: 1262-1274. 